Böler, T. / Sosyal Bilimler Araştırmaları Dergisi. 2, (2008): 54-61

\title{
Dede Korkut Hikâyeleri'nde Şart Cümleleri
}

\section{Tuncay Böler ${ }^{\text {a }}$}

\section{Özet}

Dede Korkut Hikâyeleri Türk dilinin üzerinde en çok çalışılan ve böylelikle kendine hak ettiği değer en yüksek dereceden verilen eserleri arasındadır. Tabii ki bu çok işlenmişlik eserin içinde barındırdığı dil malzemesiyle de doğru orantılıdır.

$\mathrm{Bu}$ araştırmadaki hareket noktamız olan şart cümleleri Dede Korkut Hikâyeleri'nde pek sık başvurulan cümle tiplerindendir.

Çalışmamızda hikâyelerdeki şart cümleleri, kuruluş ve ifade özellikleri bakımından tasnif edilmiş, sistematik bir şekilde verilmiştir.

Anahtar sözcükler: Dede Korkut Hikâyeleri, cümle bilgisi, şart cümleleri.

\section{Conditional Sentences in Dede Korkut Tales}

Abstract
Dede Korkut Tales are among the ones that were written so much on Turkish language and thus they are deserved to be one of the most important masterpieces. Surely, these studies have a direct proportion with the language materials that the masterpiece includes.

Conditional sentences, our starting point in this study, are mostly used sentences in Dede Korkut Tales.

In our study conditional sentences in the tales were classified with regard to forming and expressing features and given systematically.

Key words: Dede Korkut Tales, syntax, conditional clauses.

Orhun Kitabeleri'nden beri dilimizde yer alması dolayısıyla uzun bir kullanım alanına sahip şart cümleleri üzerinde şimdiye kadar birçok araştırma yapılmıştır ${ }^{\mathrm{b}}$. Söz konusu araştırmalara bakıldığında hepsinde şart cümleleriyle

${ }^{a}$ Yrd. Doç. Dr. Gaziosmanpaşa Üniversitesi, Eğitim Fakültesi, Tokat.

${ }^{\mathrm{b}}$ Bunlardan bazıları aşağıda verilmiştir:

Gülşat Aygen Tosun, “Türkçede Koşul Tümcelerinin Batı Sözdizimsel ve Anlambilimsel Özellikleri”, XI. Dilbilim Kurultayı, ODTÜ Eğitim Fakültesi Yabancı Diller Eğitimi Bölümü Yayınlar1, 1997, s. 35-45.

Hatice Şahin, “Eski Anadolu Türkçesi'nde Şart Cümlelerinin Durumuna Bir Bakış”, XI. Millı̂ Türkoloji Kongresi, 15-19 Eylül 1997, İstanbul. EJOS VII (2004) Nu.:12, 1-9 ISSN 0928-6802

Hayati Develi, “\{sA\} Morfemli Yardımcı Cümleler ve Bunlarla Kurulan Birleşik Cümleler Üzerine Bir İnceleme”, Ankara 1997, Türk Dili ve Araştırmaları Yıllığı Belleten 1995, s. 115-152.

Kemal Eraslan, “-sar/-ser İsim-Fiil Ekinin Yapısı ve Fonksiyonları", Hasan Eren Armağanı, TDK Yayınları, Ankara 2000, s. 92-127.

Kerime Üstünova, "Dilek Kiplerinde Zaman Kavramı", Ankara Kasım 2004, Türk Dili, c. LXXXVIII, sayı 635, s. 678-686. 
Böler, T. / Sosyal Bilimler Araştırmaları Dergisi. 2, (2008): 54-61

ilgili çeşitli konuların ele alındığı, tartışıldığı ve bunların günümüzdeki araştırmalara kaynaklık ettiği görülmektedir.

Bizim araştırmamız Dede Korkut Hikâyeleri'nde geçen şart cümleleri üzerinde olmuştur. Eserdeki şart cümleleri çalışmamızda kuruluş ve ifade özelliği bakımından tasnif edilmiştir ${ }^{c}$. Bununla amacımız Türk dilinin en önemli eserlerinden biri olan ve Türk dilinin doğal yapısını en güzel bir biçimde ortaya koyan Dede Korkut Hikâyeleri'nden hareketle şart cümlelerinin dilimizdeki değişim ve gelişiminin tespitine imkân sağlamak ve konuyla ilgili yapılacak yeni araştırmalara malzeme oluşturmaktır.

\section{Kuruluş Bakımından Şart Cümleleri}

Dede Korkut Hikâyeleri'nde şart cümlelerinin esas kuruluşu, temel cümleye eklenen yan cümlenin bir $-s A$ şart eki alması şeklindedir:

Urlaşuban sular taşsa deniz tolmaz. (s. 73)

Kamın akan yügrük sudan bir oğul akıtdun ise digil mana. (s. 87)

Oğuz zamanında bir yigit ki ivlense oh atar idi, okı ne yirde düşse anda gerdek diker idi. (s. 129)

Oğul anun içün yağı dirler ki biz anlara yetsevüz öldürürüz, anlar bize yetse öldürür didi. (s. 158)

Karşu yatan kara tağlar karısa

Otı bitmez il yaylamaz. (s. 171)

Kayıduban buradan oğul ive varsam

Ağça yüzlü anan karşu gelüp oğul dise

A ̆g elleri ardına bağlu diyeyin mi. (s. 171)

Kırk bin er yağı gördüm ise kıya bakdum. (s. 236)

pekiştirilir:

Hikâyelerde $-s A$ ekinden önce Farsça eger edatı kullanılarak şart anlamı

Kerime Üstünova, “Türkçede Zaman Kavramı ve İşlenişi”, Bursa 2005, Uludağ Üniversitesi Fen-Edebiyat Fakültesi Sosyal Bilimler Dergisi, y1l 6, say1 9, s. 187-201.

Mehmet Uzman, Türkçede Şart Kipi ve Emir Kipinin Tarih İçindeki Gelişimi, Trakya Üniversitesi Sosyal Bilimler Enstitüsü Yüksek Lisans Tezi, Edirne 1992.

Metin Karaörs, “Türk Dilinde Şartlı Birleşik Cümle ve Nevayi'nin II. Divanı Nevadirü'şŞebab'da Şartlı Birleşik Cümleler”, V. Uluslararası Türk Dili Kurultayı Bildirileri, TDK Yayınları, Ankara 2004, s. 1637-1671

Özen Yaylagül, Türk Dilinde -sA(r)'lı Kuruluşlar, İnönü Üniversitesi Sosyal Bilimler Enstitüsü Doktora Tezi, Malatya 2002.

Vecihe Kılıçoğlu, “Şart Kipi”, Ankara Şubat 1954, Türk Dili, c. III, sayı 29, s. 254-258.

Zeynep Korkmaz, “-sa/-se Dilek-Şart Kipi Eklerinde Bir Yapı Birliği Var mıdır?”, Türk Dili Üzerine Araştırmalar Birinci Cilt, Ankara 1995, 160-167.

c Bu araştırmada kullanılan ana kaynak: Ergin, Muharrem, Dede Korkut Kitabı I, II, TDK Yayınları, Ankara 1997. 
Böler, T. / Sosyal Bilimler Araştırmaları Dergisi. 2, (2008): 54-61

Dirse Han eger oğlançuğın görür ise arturmaz bizi hep kırar didiler. (s. 90)

Eger senün oğlun olmasayidi bizüm malumuz Gürcistanda gitmiş idi, hepümüz tutsak olmuş idi didiler. (s. 120)

$\mathrm{Bu}$ yigidün sözi yügrük, eger elinde hüneri var ise didi. (s. 188)

Eger Begil bunda imiş ise

Giceye degin cenk ideyidük. (s. 223)

Ancak kimi örneklerde eger' in cümle başına getirilmesiyle birlikte yan cümlenin yüklemi şart kipiyle değil, ek-fiil ile çekimlenebilir:

Eger sağdur esendür ahşam olmadın gine ben sana gelürem, ordum sağ esen degül ise başunuza çara idün, men dahı gitdüm didi. (s. 100)

Bazen de yan cümlenin yükleminde bulunan $-s A$ şart ekine bağlı olarak cümlenin başına her ne, her kim belirsizlik sözcükleri getirilir ${ }^{\mathrm{d}}$ :

Her ne iş olsa Korkut Ataya tanışmayınça işlemezler idi. (s. 73)

Her ne ki buyursa kabul iderler idi. (s. 73)

Her kim ol üç canavarı bassa yense öldürse kızumı ana virürem diyü va' de eylemiş idi. (s. 185)

$y A$ ! ünleminin $y$-'si eriyerek kısalmış bir biçimi olan $-A$ ! ünlemi ile genişletilen (Korkmaz, 2003: 692) ve güçlü bir dilek ifade eden şart şekli, Dede Korkut Hikâyeleri' nde aşağıdaki örneklerde yer almaktadır:

Öldürsene didiler. (s. 84)

Bunda laf urup nidersin, çünki er dilersin varup babanı kurtarsana ne, on altı y1ldur tutsakdur didi. (s. 200)

Hikâyelerde -IncA zarf-fiilinden sonra şart kipinde çekimlenmiş bir fiilin kullanıldığı görülmektedir. Burada söz konusu zarf-fiilden sonra gelerek - $m A s A$ biçiminde olumsuz şart kipiyle çekimlenen fiiller, kendinden hemen önce bulunan olumlu zarf-fiil yapısına paralel olarak olumsuzluk ifade etmekte ve istenen, arzu edilen bir durumu göstermektedir ${ }^{\mathrm{e}}$ :

Dede Korkut bir dahı soylamış: Sarp yorır-iken kazılık ata nâmerd yigit binebilmez, bininçe binmese yig. (s. 74)

Çalup keser öz kılıcı muhannetler çalınça çalmasa yig. (s. 74)

Ata adını yorıtmayan hoyrad oğul ata bilinden ininçe inmese yig, ana rahmine düşinçe toğmasa yig. (s. 74)

\footnotetext{
${ }^{\mathrm{d}}$ Şart cümlelerinin Eski Anadolu Türkçesi’nde bu ve yukarıdaki biçimdeki kullanımları için bk.: Hatice Şahin, "Eski Anadolu Türkçesi’nde Şart Cümlelerinin Durumuna Bir Bakış", XI. Millî Türkoloji Kongresi, 15-19 Eylül 1997, İstanbul. EJOS VII (2004) Nu.:12, 1-9 ISSN 0928-6802.

${ }^{\mathrm{e}}$ Orhan Şaik Gökyay ise kitabının gerundiumlar bölümünde şart kipiyle çekimlenmiş bir fiilden önce gelen bu türden zarf-fiil kullanımları için, burada fiilin bir zaman sınırı vermekten çok, gelecek zamanın şartı gibi bir anlam vermekte olduğu görülür, dedikten sonra -IncA ekini, eylemleri veya kavramları kıyaslamaya yarayan bir gerundium saymanın daha doğru olacağını belirtmektedir (Gökyay, 1973: CCVII).
} 
Böler, T. / Sosyal Bilimler Araştırmaları Dergisi. 2, (2008): 54-61

Yalan söz bu dünyede olınça olmasa yig. (s. 74)

At yimeyen acı otlar bitinçe bitmese yig. (s. 74)

Adam içmez acı sular sızınça sızmasa yig. (s. 74)

Aşağıdaki örneklerde ise şart kipi, bak- ve gör-fiillerinden sonra şart fonksiyonunu kaybederek bir izah unsuru, $k i$ ' nin açıklama fonksiyonuna benzer bir izah unsuru, aşağı yukarı bir izah edatı durumunda kullanılmıştır (Ergin, 1997: 481).

Baksa görse bir derenin içine karga kuzgun iner çıkar, konar kalkar. (s. 88)

Baksa görse oğlunçuğı alça kana bulaşmış yatur. (s. 88)

Öte yandan Muharrem Ergin'in İsimlerle kullanılışı bugünkünden farksız olan bu fiil, eserde fiil şekilleri ile çok geniş olarak ve çok değişik fonksiyonlarda çok işlek ve oynak bir şekilde kullanılmış, partisipli şekillerden başka fiillere de getirilerek âdeta yepyeni, bilinen kiplerden apayrı kipler meydana getirmiştir (Ergin, 1997 II: 473), dediği ol- yardımcı fiilinin şart kipindeki çekimleri Dede Korkut Hikâyeleri'nde dikkati çeken diğer yapılardır:

Ağız açup öger olsam üstümüzde Tanrı görklü. (s. 75)

A ̆g sakallu atanı ağ pürçeklü ananı sorar olsan sağdur Bamsı. (s. 134)

Dimez olsan yana göyine kargaram Kazan sana didi. (s. 165)

Yaylar olsam menüm gorum olsun. (s. 183)

Allah menüm ivümi kurtaraçak olur ise seni emirahur eyleyeyin didi. (s. 105)

Götüreçek olur isen yigitligüm seni tutsun ağaç. (s. 109)

Bigler Allah Ta'âla mana bir kız vireçek olur ise, siz tanık olun, menüm kızum Pay Büre Big oğlına bişik kertme yavuklu olsun didi. (s. 117)

Gelmez olsan Pay Piçen kızı Banı Çiçegi aldurdun bellü bilgil. (s. 134)

Dimez olur isen yana göyine kargaram Kazan sana didi. (s. 164)

Aşağıdaki örnekte ise degülmiseyidi biçimindeki şart şeklinde yer alan degül sözü de bir yardımcı fiil olan ol- gibi kullanılmıştır:

Uruz aydur: Ağzun kurısun ana, dilün çürisün ana, ana hakkı Tanrı hakkı degülmiseyidi kalkubanı yirümden turayidüm, yakan ile boğazundan tutayidüm... (s. 107)

Şart ifade eden birden çok cümlenin bulunduğu ve kimi araştırmacılar tarafından zincirleme şart cümlelerif olarak adlandırılan yapılar eserde aşağıdaki örneklerde yer almaktadır:

Ol Mekkeye sağ varsa esen gelse sıdkı bütün hacı görklü. (s. 75)

\footnotetext{
${ }^{\mathrm{f}}$ Ayrıntılar için bk.: Hayati Develi, "-sA Morfemli Yardımcı Cümleler ve Bunlarla Kurulan Birleşik Cümleler Üzerinde Bir İnceleme", Türk Dili ve Araştırmaları Ylllı̆̆ Belleten 1995, Ankara 1997, s. 115-152.
} 
Böler, T. / Sosyal Bilimler Araştırmaları Dergisi. 2, (2008): 54-61

Ol zamanda bir oğlan baş kesmese kan dökmese ad komazlar idi. (s. 118)

Bir yigit olsa dirisi haberin getürse çırgap çuha altun akça virür idüm. (s. 131)

Karıçuk anam karşu gelse

Meni sana sorsa

Baba toğrı haber virgil. (s. 169)

Karımından dönmese kaçmasa erlik yahşı. (s. 203)

Eserde $-s A$ eki gerek sözcüğüyle birlikte gereklilik kipini anlatmak üzere kullanılmıştır:

Bu üç nesneyi ana armağan aparsavuz gerek idi didiler. (s. 119)

Haberi yok ki alaçağı ala gözlü kızun otağı olsa gerek. (s. 122)

Kan Turalı aydur: Baba bu sözi sen mana dimemek gerek idün, çünki didün elbetde varsam gerek, başuma kahınç yüzüme tohınç olmasun, kadun ana big baba esen kalun didi. (s. 186)

Kan Turalı aydur: Yok elbette öldürsem gerekdür didi. (s. 197)

$-s A$ ekiyle yapılan şekillerin kipten çok zarf-fiil özelliklerine sahip olduğu, bu sebeple $-s A^{\prime}$ 'nı kip eki değil şart zarf-fiili sayılması gerektiğini belirtenler de vardır ${ }^{g}$. Hikâyelerde şart kipi özellikle aşağıdaki örnekte, bir zarffiil gibi kullanılmıştır:

Eyle olsa sultanum, Karaça Çoban sapan çatlatdı, dünya âlem kâfirün gözine karangu oldı. (s. 110)

(Öyle olunca sultanım, Kara Çoban sapan çatlatt, dünya âlem kâfirin gözüne karanlık oldu.)

İfade Özellikleri Bakımından Şart Cümleleri

Hikâyelerde ifade özellikleri bakımından hem gerçek ve gerçek olmayan şart ifade eden hem de istek ifade eden şart cümlelerine rastlanmaktadır.

\section{Gerçek ve Gerçek Olmayan Şart İfade Edenler}

Bir yigidün kara tağ yumrısınça malı olsa yığar direr taleb eyler, nasibinden artuğın yiyebilmez. (s. 73)

\footnotetext{
g Gürer Gülsevin, “Türkçede -sA Şart Gerundiumu Üzerine”, Türk Dili, Ankara Kasım 1990, say1: 467, s. 276-279.

Leylâ Karahan, “-sa/-se Eki Hakkında”, Türk Dili, Ankara Şubat 1994, sayı: 516, s. 471-474.

Bu bakış açısıyla ilgili itiraz ve değerlendirmeler için bk.:

Hayati Develi, “-sA Eki Nedir? Kip mi, Zarf-fiil mi?”, İlmî Araştırmalar, İstanbul 1995, c. I, s. 89-94.

Mustafa Öner, “-matı/-meti Gerundiyumu Hakkında”, 3. Uluslar Arası Türk Dil Kurultayı, TDK Yayınları, 1999, s. 833-840.
} 
Böler, T. / Sosyal Bilimler Araştırmaları Dergisi. 2, (2008): 54-61

Kara eşek başına uyan ursan katır olmaz, karavaşa ton geyürsen kadın olmaz. (s. 74)

Kara tonlu azgun dinlü kâfirlere bir oğul aldurdun ise digil mana. (s. 87)

Atduğı taş yire düşmez idi, yire dahı düşse toz gibi savrılur idi, ocak gibi obrılur idi, üç yıla dak taşı düşdügi yirün otı bitmez idi. (s. 109110)

Beyrek aydur: Mere çobanlar bir kişi yolda taş bulsa yabana atar, siz bu yolda bu taşı niçün yığarsız? (s. 137)

Sağ esen çıkup gelse

Karşu yatan kara tağlar sana yaylak olsun. (s. 150)

Kazan aydur: Oğul bin kâfir öldürsen kimse senden kan davilemez. (s. 158)

Yad, kâfir gelse başın Oğuza armağan gönderür idi. (s. 216)

Aruk olsa kulağın deler idi avda bellü olsun diyü, amma semüz olsa boğazlar idi. (s. 217)

Hatunı ayıttı: Big yigidüm, kalabalık yağı gelse kayıtmaz idün, butuna ala oh tohınsa inlemez idün, kişi koynında yatan halalına sırrın dimez mi olur, nedür halun didi. (s. 219)

$\mathrm{Al}$ aygır kaçan kim yağı kohusın alsa ayağın yire döger idi, tozı göge çıkar idi. (s. 221)

Kardaşsuz miskin yigit ensesine yumruk tokınsa

Ağlayuban dört yanına bakar olur

Ala gözden acı yaşın döker olur. (s. 228)

Üç Ok Boz Ok yığnak olsa Kazan ivin yağmaladur idi. (s. 243)

Kaçan Kazan ivin yağmalatsa halalınun elin alur taşra çıkar idi, andan yağma iderler idi. (s. 243)

\section{İstek İfade Edenler}

Pay Püre aydur: Menüm dahı oğlum olsa, Han Bayındurun karşusın alsa tursa kullık eylese, men dahı baksam sevinsem kıvansam güvensem didi. (s. 116)

Beyrek aydur: Sultanum meni kosan da şölen yimeginün yanına varsam, karnum açdur toyursam didi. (s. 145)

Hak Ta'âla atamun könline rahmet eylese, kebin kesüp meni ol yigide virse, bunun kibi yigit hayıf ola ki canavarlar elinde helak ola didi. (s. 188)

Kaytabanun mayasını yüklü kodum

Ner midür maya midur anı bilsem. (s. 205)

Kara ilüm koyunını yüklü kodum

Koç mıdur koyun mıdur anı bilsem. (s. 205)

Ala gözlü görklü halalum yüklü kodum 
Böler, T. / Sosyal Bilimler Araştırmaları Dergisi. 2, (2008): 54-61

İrkek midür kız mıdur anı bilsem. (s. 205)

Hey kırk işüm kırk yoldaşum

Yügrük olsa yarışsam

Güçlü olsa güreşsem

Hak Ta' âla inayet eylese

Üç canavarı öldürsem

Gözeller serveri saru tonlu Selcen Hatunı alsam

Atam anamı ivine dönsem

Hey kırk işüm kırk yoldaşum

Kırkunuza kurban olsun menüm başum diyü söyler idi. (s. 187-188)

\section{Sonuç}

Türk dili ve araştırmaları bakımından eşsiz bir kaynak olan (Gökyay, 1973: CLXXXVII) Dede Korkut Hikâyeleri üzerinde yaptığımız bu araştırmadan elde ettiğimiz sonuçlar şunlardır:

Şart cümlelerinin esas kuruluşu yan cümlenin $-s A$ şart eki alması şeklindedir.

Bunun yanında eger edatı kullanılarak şart anlamı pekiştirilmiştir.

Eger edatı cümle başına getirildiğinde yan cümlenin yüklemi ek-fiil ile çekimlenebilmiştir.

Kimi şart cümlelerinde her ne, her kim belirsizlik sözcükleri şart ekine bağlı olarak cümle başında kullanılmıştır.

-sAnA biçiminde istek ifade eden şart şeklinin hikâyelerde kullanıldığı tespit edilmiştir.

-IncA zarf-fiilinden sonra gelen olumsuz şart biçimi, istenen, arzu edilen bir durumu göstermektedir.

Baksa görse şeklindeki yapı şart fonksiyonunu kaybetmiş, bir izah edatı gibi kullanılmıştır.

Ol- yardımcı fiilinin sıfat-fiillerden sonra şart eki alarak kullanılan biçimleri (yaylar olsam, dimez olsan, götüreçek olur isen örneklerinde olduğu gibi) oldukça fazladır.

Şart ifade eden birden çok yan cümle temel cümleye bağlanabilmektedir.

-sA gerek, gereklilik kipini anlatmak üzere kullanılmıştır.

Hikâyelerde ifade özellikleri bakımından hem gerçek ve gerçek olmayan hem de istek ifade eden şart cümleleri bulunmaktadır.

\section{Kaynaklar}

Ergin, M. (1997), Dede Korkut Kitabı I Giriş-Metin-Faksimile, TDK Yayınları, Ankara.

Ergin, M. (1997), Dede Korkut Kitabı II İndeks-Gramer, TDK Yayınları, Ankara.

Gökyay, O. Ş. (1973), Dedem Korkudun Kitabı, Başbakanlık Kültür Müsteşarlı̆̆ı Kültür Yayınları, İstanbul 1973. 
Böler, T. / Sosyal Bilimler Araştırmaları Dergisi. 2, (2008): 54-61

Korkmaz, Z. (2003), Türkiye Türkçesi Grameri (Şekil Bilgisi), TDK Yayınları, Ankara. 